\title{
Conservation and Improvement Strategy for Fogera Cattle: A Lesson for Ethiopia Ingenious Cattle Breed Resource
}

\author{
Assemu Tesfa, ${ }^{1}$ Dilip Kumar, ${ }^{2}$ Solomon Abegaz, ${ }^{3}$ and Getinet Mekuriaw ${ }^{2,4}$ \\ ${ }^{1}$ Andassa Livestock Research Center, P.O. Box 27, Bahir Dar, Ethiopia \\ ${ }^{2}$ Bahir Dar University Colleges of Agriculture and Environmental Science, P.O. Box 5501, Bahir Dar, Ethiopia \\ ${ }^{3}$ Ethiopian Institute of Agricultural Research (EIAR), P.O. Box 2003, Addis Ababa, Ethiopia \\ ${ }^{4}$ International Livestock Research Institute (ILRI), P.O. Box 5689, Addis Ababa, Ethiopia
}

Correspondence should be addressed to Assemu Tesfa; assemu546@gmail.com

Received 20 August 2016; Accepted 12 January 2017; Published 6 February 2017

Academic Editor: Innocenzo Muzzalupo

Copyright (C) 2017 Assemu Tesfa et al. This is an open access article distributed under the Creative Commons Attribution License, which permits unrestricted use, distribution, and reproduction in any medium, provided the original work is properly cited.

\begin{abstract}
The paper is initiated to design appropriate conservation strategies and breeding scheme for Fogera cattle breed that will be used as a guide for other Ethiopian indigenous cattle breed. Two types of data, on-farm and on-station, were used; the on-farm data was collected from three districts, namely, Fogera, Dera, and Bahir Dar Zuria; those are expected as the home of the breed. A total of 150 farmers, which are knowledgeable and having at least one cattle of Fogera phenotype in their herd, were purposively selected and interviewed. Additionally, farmer's focus group discussion (FGD) was conducted to capture the historical background, population, and distribution of the breed. SPSS (version 16) and index method was used to analyze the quantitative and scoring data's, respectively. A meeting at national and regional level was also conducted to evaluate the existing conservation strategy and to identify the major stakeholders for the strategy. The main reasons to conserve Fogera breed are due to presence of interrelated constraints, presence of unique traits of the breed, better attitude of farmers, and decreasing population trend of the breed. Community-based in situ conservation strategy, to ensure the participation of the community, was designed for the breed. With the conservation strategy, related activities like feed development, animal health interventions, market linkage, and development of cooperatives will be implemented to improve the working environment. The stakeholders that are identified as an actor in the strategy should realize their honest participation for the sustainability of conservation and improvement of the breed.
\end{abstract}

\section{Introduction}

The conservation of local breeds should be considered whenever the development of animal production systems is discussed [1]. Conservation of genetic diversity is essential to the long-term survival of any species, particularly in light of changing environmental conditions [2], and is essential for management of threatened and endangered species [3] for sustainable use [4]. In the context of setting priorities for conservation, Barker [5] and Zárate and Markemann [6] suggested that the only rational criteria are the likelihood of extinction of a breed and the degree to which it possesses unique genes and threats the breed faces and farming shift in the production area.

In Ethiopia, four cattle ranches are operating ex situ conservation measures of indigenous cattle breeds of the country.
These ranches are Goba ranch that conserves Arsi cattle breed; Abernossa ranch that conserve Ethiopian Boran cattle; and Metekel and Andassa ranch that conserve Fogera cattle breed $[7,8]$. But it is also clearly indicated that the success of these conservation efforts had shortcomings of political instability and/or inconsistency of development policies, limited stakeholder participation, and limitation of interventions in scope and scale that underestimates the conservation efforts [9].

Today, a large number of indigenous breeds or varieties in the developing world are at risk of becoming extinct [10]; likewise, at the moment breeds like Sheko cattle are highly threatened as a result of interbreeding; others like Fogera, Begayit, Ogaden, and Borena cattle breeds are also facing various degrees of threat [11]. The total population number of Fogera cattle had declined from time to time and it had 


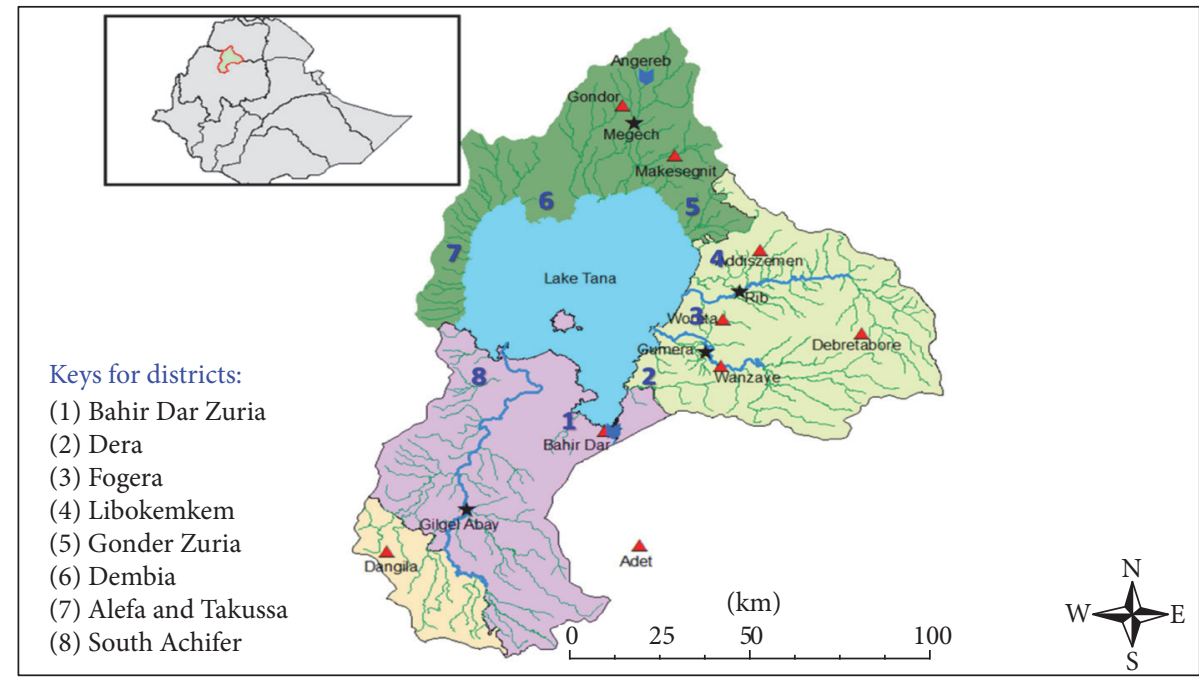

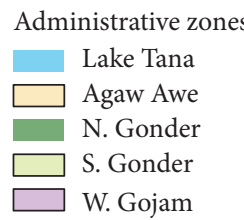

FIgURE 1: Districts of Fogera cattle breed distribution.

declined in alarming rate from 1980's [12] to 2000's [13] that need conservation effort for future potential use of the breed. The main threatening problems that lower both the productivity and population are genetic admixture, shift of production system, shrinkage of grazing land, and poor management practices. These problems coupled with absence of sustainable conservation strategies for indigenous cattle breed resources of the country leads to the extinction of these breeds. Therefore, this paper is initiated to identify the grassroots problems and to design appropriate conservation strategies and breeding scheme for Fogera cattle breed that will be used as a lesson for other Ethiopian indigenous cattle breed resources.

\section{Material and Methods}

2.1. Distribution of Fogera Cattle Breed. Fogera cattle breed is among the 27 [14] recognized indigenous cattle breeds of Ethiopia. The breed is reared in districts surrounding Lake Tana and is one of the main populated and productive breed in Amhara region [15] and in the country [16]. Additionally, the breed is found and conserved at Andassa Livestock Research Center (ALRC) and Metekel Fogera Cattle Conservation Ranch (MFCCR) and their surrounding kebeles. Figure 1 indicates the districts where the breed is distributed.

2.2. Description of Nucleus Herd at ALRC. Currently the center had 332 breeding females and 101 breeding males in various age groups (Table 1); the first group is $0-8$ months which is the weaning age of the breed, $8-19$ months where females run with bull and males are distributed to famers
TABLE 1: Current Fogera cattle nucleus herd population at ALRC.

\begin{tabular}{lccccc}
\hline \multirow{2}{*}{ Sex } & \multicolumn{5}{c}{ Age group (month) } \\
& $0-8$ & $8-19$ & $19-32$ & $>32$ & Total \\
\hline Male & 50 & 46 & 0 & 5 & 101 \\
Female & 58 & 76 & 85 & 113 & 332 \\
\hline Total & 108 & 122 & 85 & 118 & 433 \\
\hline
\end{tabular}

and community-based conservations, 19 months and above where females continue to be included with nucleus herd and males for natural mating based on their pedigree. The total Fogera herd is grouped to six (four natural mating herd, one AI herd, and one bull herd). Breeding bulls used for the herd are sourced from two centers namely, Metekel Ranch and the center among the farm born male stock with maximum birth weight, weaning and yearling weight, good morphological conformation, unrelated pedigree, and better health condition of the testis and scrotum.

2.2.1. Herd Management. All animals of the farm are subjected to graze during the day for eight hours in their herd and kept by individual day watchmen. During night time, the herds are yarded separately in their respective barn designed as loose housing system and guarded by guards. In addition to grazing, all the herds also feed conserved hay collected from the center; milking cows are supplemented with concentrate feed, which consists mainly of mixture of maize (Zea mays) and nuge (Guitozia abyssinica) seed cake. The animals were watered from Andassa river and spring water during wet season for young and sick animals which stayed at barn. 
The center is water logged area; though to prevent internal and external parasites, strategic mass treatment against internal parasites was conducted twice a year, at the start and end of the rainy season. Animals were treated for ectoparasites fortnightly in peak season and monthly when the infestation level was low [17]. The prevention scheme focused on vaccination against anthrax, blackleg, and pasteurellosis once in every six to eight months and once per year for CBPP.

2.3. Breeding Program. In the breeding program both natural mating with Fogera bulls and artificial insemination with Holstein Friesian semen were used to produce Fogera and F1 calves, respectively. The pure breed herds are kept with selected bulls (45-50 breeding cows with one breeding bull) and mating was done at the field and registration is done by watchmen. The F1 herds of crossbreeding unit (CBU) are kept and breeding is done by AI for rising of F1 and F2 generations for distributing to the farmers after pregnancy has been confirmed with a subsidized cost. Calves born at the farm are registered, weighed before first suckling, and tagged immediately after birth. Sex of the calf, sires, and dams ID are all also recorded in the field record book and these pieces of information are then transferred to the individual cow's record card and century book; and a new card is entered for each calf. All calves are allowed to run and suckle their dams until they wean. After weaning the best heifers from the pure Fogera breeding unit (FBU), through their performance data (birth and weaning weight, body conformations), were kept as a replacement herd.

2.4. On-Farm Data Source. Primary data was collected from three districts, namely. Fogera, Dera, and Bahir Dar Zuria; those are expected as the source of the breed. From Bahir Dar and Dera districts two Peasant Associations (PAs) and one PA from Fogera district (where Fogera cattle breed conservation and improvement are practiced) were purposively selected based on the distributions of the breed. A total of 150 farmers (30 farmers from each PA), which are knowledgeable and having at least one cattle of Fogera phenotype in their herd, were purposively selected and interviewed. Additionally, farmer's focus group discussion (FGD) was conducted to capture the historical background, population trend, and distribution of the breed.

The questioner data were screened and cross-checked for reliability and consistency; questions which were not clearly addressed were removed. The purpose of livestock keeping, major constraints of the breed, merits and demerits of the breed, and conservation necessities were analyzed and summarized by SPSS [18] and index method. Index was computed with the principle of weighted average according to the following formula:

$$
\begin{aligned}
\text { Index }= & R_{n} * C_{1}+R_{n-1} * C_{2} \cdots R_{1} \\
& * \frac{C_{n}}{\sum R_{n} * C_{1}+R_{n-1} * C_{2} \cdots R_{1}},
\end{aligned}
$$

where $R_{n}$ is value given for the least ranked level (e.g., if the least rank is 5 th rank, then $R_{n-5}, R_{n-1}=4$, and... $\left.R_{1}=1\right) . C_{n}$ is counts of the least ranked level (in the above example, the count of the 5 th rank is $C_{n}$, and the counts of the 1st rank are $\left.C_{1}\right)$.

2.5. Method to Design Conservation Strategies. To design appropriate conservation strategy and develop a feasible breeding scheme to support and update the existing conservation strategy adopted by ALRC and Metekel sites for Fogera breed $[7,8]$, detailed evaluations of the existing once were done with the participation of various stakeholders. Two meetings (one national and one regional) were conducted in two rounds to evaluate the existing strategy and to develop feasible strategy based on the current situation of the breed. The stakeholders which were identified as actors on the conservation and improvement plan were Ethiopian Institute of Agricultural Research (EIAR), International Livestock Research Institute (ILRI), Ethiopian Society of Animal Production (ESAP), Ethiopian Institute of Biodiversity (EIB), universities (Bahir Dar and Debre Tabor university), collaborative projects, livestock agency (zone to district level), agriculture bureau and offices, and farmers. The result obtained from the meeting was used to design the conservation strategy and breeding scheme for the breed.

\section{Result and Discussion}

3.1. The Need for Conservation of Fogera Cattle Breed. Conservation of genetic resources is mainly due to keeping potentially useful genes and gene combinations; providing an insurance policy against climate change; spread of disease; and availability of feedstuffs and cultural reasons [19, 20] so as to properly utilize their potential. Conservation of Fogera cattle breed at Andassa and Metekel ranches had been underway for the past 52 and 28 years, respectively. With unique and preferred characters of the breed, its population and productivity are declined from year to year which bells intervention for conservation and improvement of the breed. The major points for the need of conservation and improvement efforts on the breed are discussed below.

3.1.1. Interrelated Constraints Facing the Breed. The major constraints for genetic conservation and improvement were absence of workable agricultural sector policy, lack of infrastructure, absence of well-defined breeding programs, poor selection strategy, and genetic gain $[19,21,22]$.

The survey result summarizes (Table 2) the major constraints that contribute to the decrements of the population as well as its productivity of Fogera cattle at its production environment. Shortage of grazing land/feed which is due to shrinkage of the grazing land for crop diversification and intensification (as Yitaferu [23] indicated from 1982 to 2003, the cropland expanded from $53 \%$ to $61 \%$, while grazing lands decreased from 21.2 to $12.6 \%$ in some kebeles around Lake Tana of Fogera district); fluctuations of the minimum temperature and increasing trends of the maximum temperature across years (Figure 2) that had an effect on feed quality production and outbreak of disease; and diseases and parasite burden related to the seasonal water load of the grazing land 
TABLE 2: Major constraints for the decreasing performance and population status of Fogera cattle.

\begin{tabular}{|c|c|c|c|c|c|c|c|}
\hline \multirow{2}{*}{ Major constraints } & \multicolumn{4}{|c|}{ Respondents $(N=150)$} & \multirow{2}{*}{ Score } & \multirow{2}{*}{ Index } & \multirow{2}{*}{ Rank } \\
\hline & 1 & 2 & 3 & 4 & & & \\
\hline Shrinkage of grazing land & 52 & 14 & 10 & 8 & 278 & 0.33 & 1 \\
\hline Shortage of land for feed development and rearing of the breed & 32 & 4 & 6 & 2 & 154 & 0.18 & 2 \\
\hline Absence of health follow-up and clinic & 2 & 26 & 4 & 2 & 96 & 0.11 & 3 \\
\hline Lack of better breeding bull & 4 & 12 & 8 & 0 & 68 & 0.08 & 4 \\
\hline Flood on grazing land and extinction of adaptive grasses & 4 & 10 & 8 & 0 & 62 & 0.07 & 5 \\
\hline Lack of family labour to manage the breeds & 0 & 16 & 4 & 0 & 56 & 0.066 & 6 \\
\hline Poor management adopted for the breed & 4 & 12 & 0 & 0 & 52 & 0.061 & 7 \\
\hline Crossbreeding to upgrade the local breeds & 6 & 4 & 6 & 2 & 50 & 0.05 & 8 \\
\hline Admixture of the breed with other highland breeds & 2 & 4 & 2 & 0 & 24 & 0.02 & 9 \\
\hline
\end{tabular}

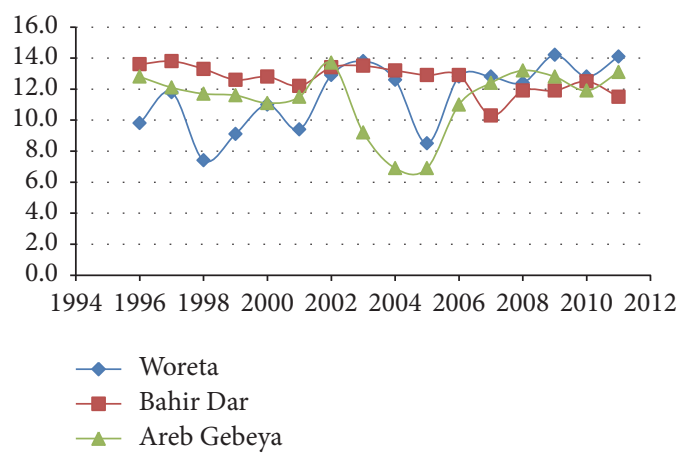

(a)

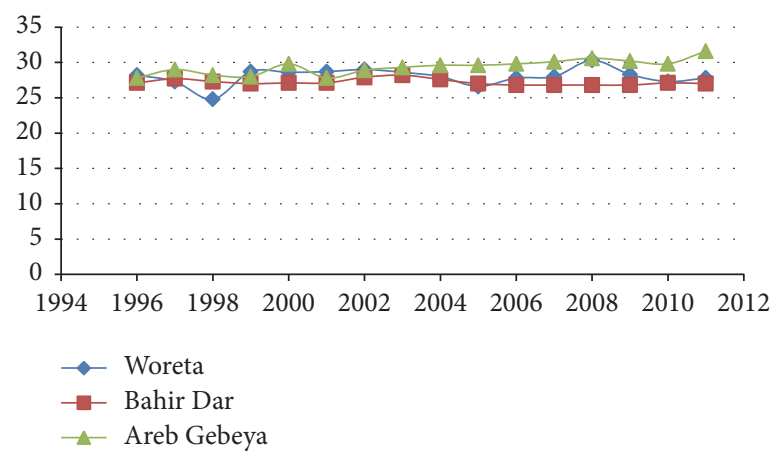

(b)

FIGURE 2: Temperature distribution across years of the working districts city: (a) minimum temperature (b) maximum temperature.

coupled with absence of health clinic (particularly at Fogera district) that were the major ones.

The focus group discussion result indicated that the major constraints were genetic admixture with highland breeds due to movement of the breed from their native areas to adjacent districts to escape the overflooding of Lake Tana and lack of better breeding bull in their production environment. Similar results on major threatening problems of Fogera breed were reported by $[13,15,24-26]$; depletion of genetic resource of Boran breed with similar threats was also reported [27, 28]. Additionally, cattle production constraints, namely. shortage of grazing land (mainly by land degradation), disease prevalence, and lack of veterinary services, were reported [29-31].

3.1.2. Presence of Unique Traits of the Breed. From the survey result and the continuous farmers' discussions, it was indicated that there is preference for Fogera cattle over other breeds due to presence of desired traits in the breed like better milk production, better selling price, better traction power, adaptability to the local environments, ability to disease resistance, and drought resistance. Advantageous and disadvantageous traits of the breed were summarized in Table 3. Additionally, respondents indicated the merits of Fogera cattle breed (Table 4).

3.1.3. Better Attitude of Farmers to Keep the Breed. The result of the survey indicates that interviewed farmers volunteered to continue and expand keeping of Fogera cattle breed (Table 5). Farmers of Fogera district (50\%) were confidential to continue in keeping of the breed while farmers $(43.33 \%)$ of Bahir Dar Zuria district indicated that they were ready to sell and change their production type which might be due to the fact that selected PAs of the district had intensified in irrigation activities and keeping of small number of crossbreeds for milk production.

3.1.4. Decreasing Population Trend of the Breed. From the total respondents used for this study, $86 \%$ of them reported that the populations of Fogera breed decrease from time to time. The respondents, $87 \%$ of Bahir Dar Zuria district, all of Fogera district, and $78 \%$ of Dera district reports, the population of Fogera breed, had declined due to dominancy of small sized zebu breeds through crossbreeding and flock change due to lack of feed and feed staffs.

The population size of the breed had decreased at an alarming rate from 800,000 in 1981 [12], to 86,800 [32], and then to 15,000 [13] based on one working district (Fogera district). Simianer et al. [33] indicated 0.43 as an extinction probability for Fogera cattle, whereas Reist-Marti et al. [34] reported that the extinction probability of the breed had increased to 0.70 and based on this rapid declining of the population, the breed can be regarded as insecure, based on the six domestic populations' risk status level [22]. The populations of Fogera breed also showed a decreased trend at 
TABLE 3: Advantageous and disadvantageous traits of Fogera cattle breed.

\begin{tabular}{|c|c|c|c|}
\hline Traits & Score & Index & Rank \\
\hline \multicolumn{4}{|c|}{ Advantages } \\
\hline Better milk production & 56 & 0.23 & 1 \\
\hline Better selling price & 42 & 0.17 & 2 \\
\hline Better traction power & 39 & 0.16 & 3 \\
\hline For fattening & 15 & 0.06 & 5 \\
\hline Hide & 13 & 0.054 & 6 \\
\hline Long living & 0 & 0 & \\
\hline Low feed consumption & 0 & 0 & \\
\hline Light heavy for mud & 0 & 0 & \\
\hline Manure source & 11 & 0.049 & 7 \\
\hline Fast growing & 15 & 0.06 & 5 \\
\hline Disease resistance ability & 13 & 0.05 & 6 \\
\hline Better butter production & 6 & 0.03 & 8 \\
\hline Adaptability & 26 & 0.11 & 4 \\
\hline Drought resistance & 3 & 0.01 & 9 \\
\hline High fertility & 1 & 0.004 & 10 \\
\hline Total & 240 & & \\
\hline \multicolumn{4}{|c|}{ Disadvantages } \\
\hline Short living & 12 & 0.18 & 2 \\
\hline High feed consumption & 42 & 0.63 & 1 \\
\hline Heavy for mud & 2 & 0.03 & 4 \\
\hline Low milk production & 0 & 0 & \\
\hline Low selling price & 0 & 0 & \\
\hline Low traction power & 0 & 0 & \\
\hline Low growth for traction & 0 & 0 & \\
\hline Not safe for fattening & 0 & 0 & \\
\hline Low milk production than exotic & 1 & 0.015 & 5 \\
\hline Low adaptability & 0 & 0 & \\
\hline Low fertility & 9 & 0.136 & 3 \\
\hline Total & 66 & & \\
\hline
\end{tabular}

the two ex situ conservation sites (Figure 3) due to shrinkage of the center's total land holding for crop seed multiplications and less attention given for the conservation of indigenous livestock resources.

\subsection{Community-Based In Situ Conservation for Fogera Cattle} Breed. The failure of conservation strategies in many African countries was due to the implementation of the strategy without clear policies, regulatory frameworks, resulting in indiscriminate, uncoordinated or uncontrolled crossbreeding activities and with limited involvement of farmers who are the final beneficiaries $[35,36]$. To overcome this failure, community-based conservation has received increasing attention from the realization that most creative and productive activities of individuals or groups in society take place in communities [37].

In the implementation of community-based in situ conservation, different steps had been followed to ensure the

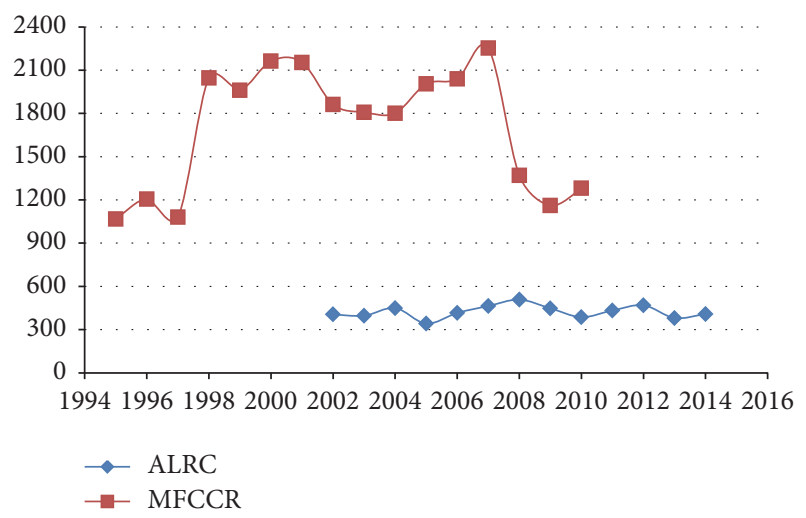

Figure 3: Total population trend of Fogera cattle at Andassa Livestock Research Center (ALRC) and Metekel Fogera cattle conservation ranch (MFCCR).

sustainability of the conservation as well as improvement strategy. From the beginning, documentation of the available resources and major livelihood of the community should be well analyzed. Finally, the impact of the strategy on the improvement of the livelihood of the community via the improvement of the local breeds under threat had been analyzed and extension and/or terminations will be followed. Figure 4 summarizes steps for the implementation of community-based conservation programme for local cattle breeds to sustainable rural livelihoods.

Community-based in situ conservation strategy helps to establish a linkage between ex situ and in situ conservation strategies. This benefits developing a continuous linkage between the nucleus herd at ALRC and village herds. In situ and ex situ conservations are seen as complementary in a way that maximizes the retention and continued evolution of the genetic qualities of farmers' varieties [38]. They also aim to avoid the loss of variation during rejuvenation and maintenance in formal gene banks. For the realization and maintenance of the breed property and pureness, breeding scheme that integrates the merits of station-based nucleus herd and village (community-based) breeding is designed; the scheme and its application are discussed below.

\subsection{Closed Breeding Scheme: For the Conservation Strategy of} Fogera Cattle Breed. There was one-way gene flow, downward from top to bottom. This means that the only source of collective genetic progress in the commercial at the top of the pyramid in the nucleus populations [39]. The breeding scheme designed and implemented for Fogera cattle at Andassa Livestock Research Center was open breeding scheme since 2007 [40]. Due to lack of identification of the pure line of the Fogera breed through molecular evidences, level of genetic admixture of the pure line with the highland zebu breeds, and inbreeding between relatives at the village herd due to lack/absence of selected breeding bull, the open nucleus breeding scheme will not be implementable. Therefore, to cope with these problems and based on the current situation of the breed, closed breeding scheme is designed (Figure 5). 
TABLE 4: Functional traits played by Fogera cattle for the community.

\begin{tabular}{ll}
\hline Functions & Component traits \\
\hline Traction/draft power & (i) Long leg for the black soil and waterlogging areas, strength to hold the harness \\
device, docile temperament & (ii) Total milk yield, lactation length, persistency, relatively short calving interval, \\
mothering ability, calf crop production, good fertility & (iii) Adaptation on water logged areas, disease resistance and tolerance to parasite \\
Adaptation & load, walking ability \\
(iv) Better birth and weaning weight, weight gain, weaning age, body conformation, & relatively voracious feeding habit, disease resistance, ease of calving and better milk \\
production
\end{tabular}

Source: focus group discussion of farmers and district experts.

TABLE 5: Attitude of farmers in keeping of Fogera cattle breed.

\begin{tabular}{|c|c|c|c|c|c|}
\hline \multirow{2}{*}{ Districts } & \multicolumn{5}{|c|}{ Attitude of the interviewed farmers } \\
\hline & Confidential to keep & Certain to keep & Ready to sell and change & Need to expand & Hard to judge \\
\hline Overall & 15.35 & 24.66 & 20 & 32.66 & 7.33 \\
\hline Fogera & 50 & 20 & 6.66 & 23.34 & 0 \\
\hline Bahir Dar Zuria & 13.33 & 33.34 & 43.33 & 10 & 0 \\
\hline Dera & 0 & 18.33 & 3.34 & 60 & 18.33 \\
\hline
\end{tabular}

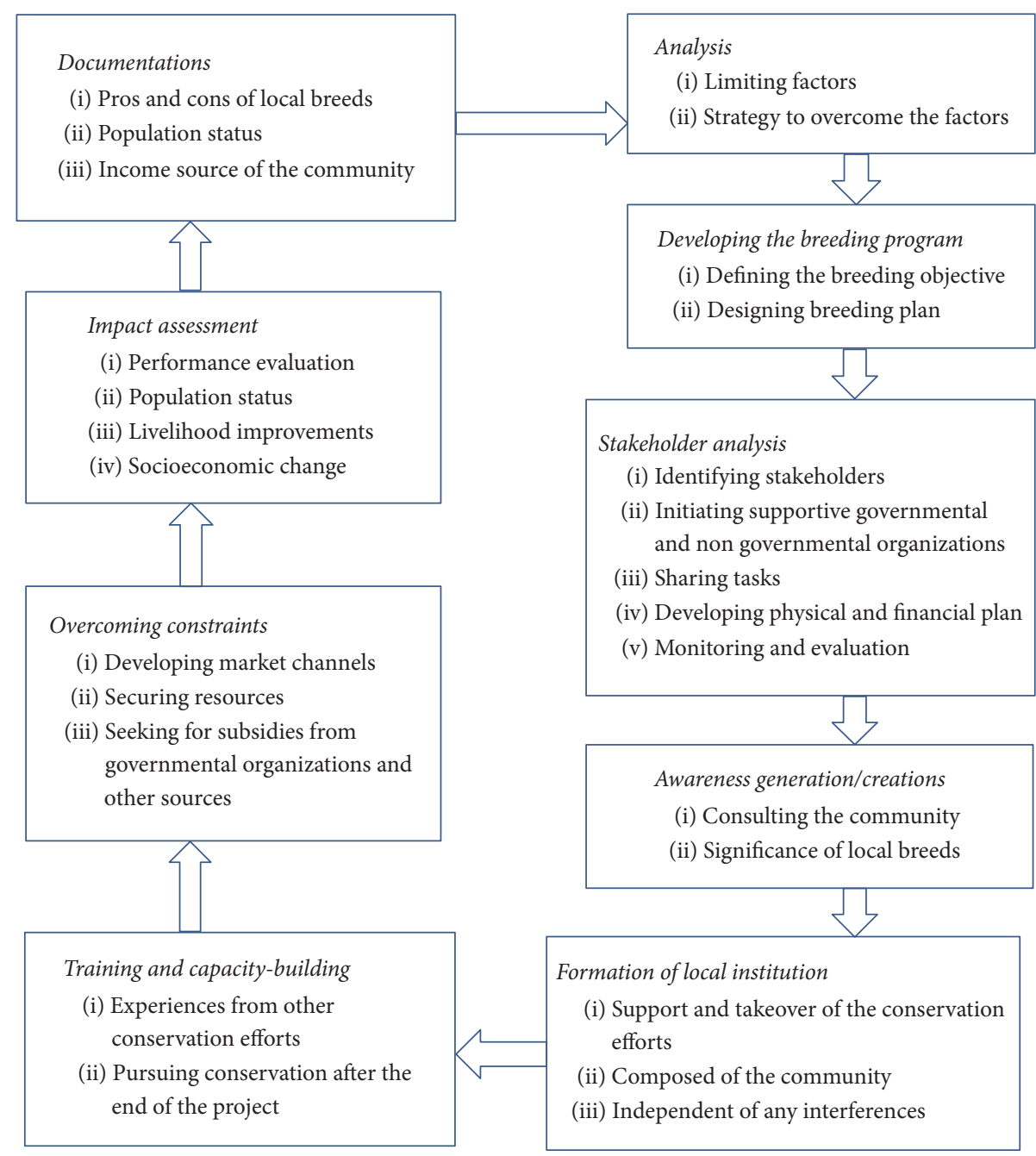

FIGURE 4: Steps for the implementation of community-based conservation program for local cattle breeds for sustainable rural livelihoods. 


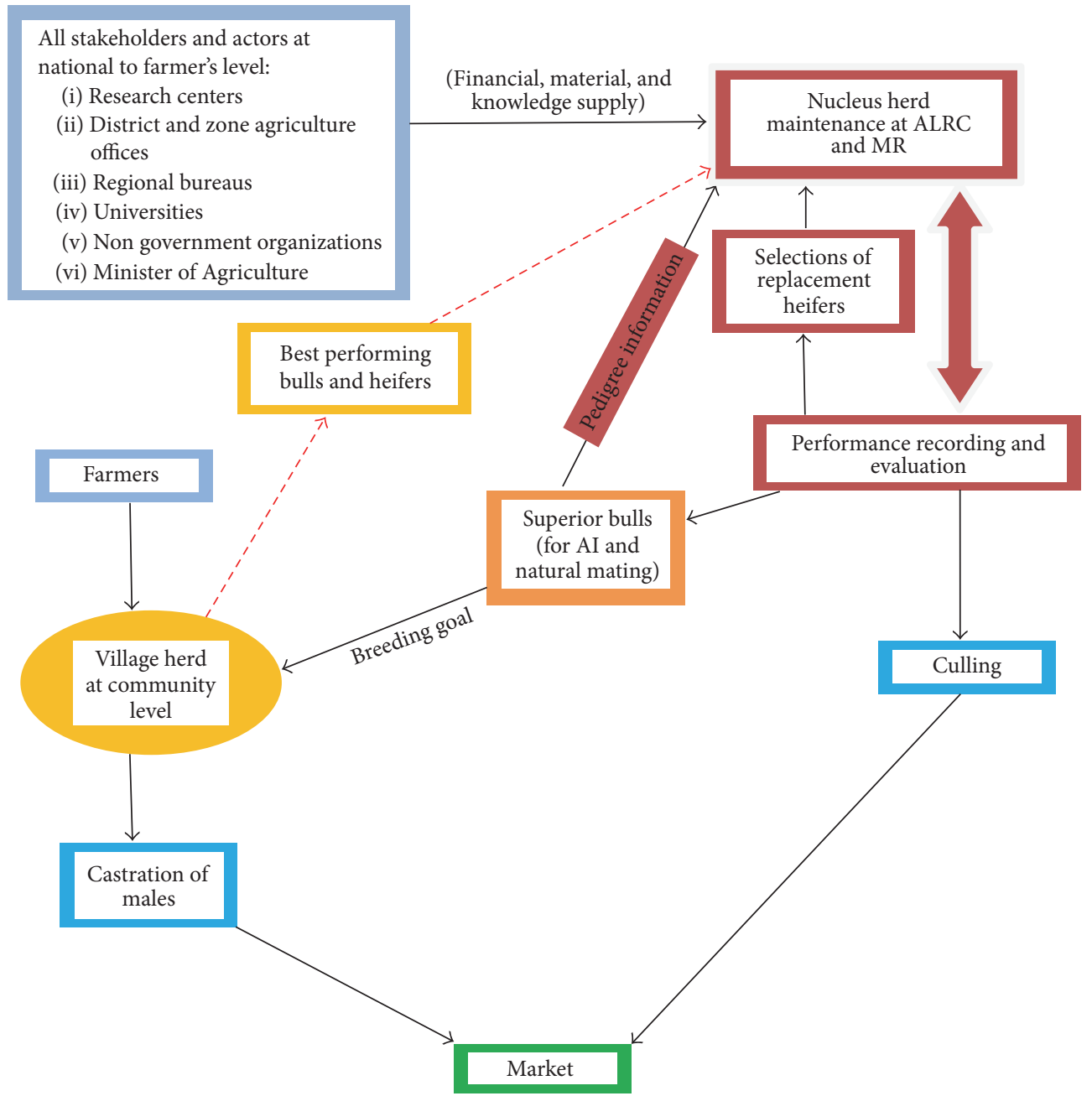

Figure 5: Closed breeding scheme for conservation and sustainable use of Fogera cattle breed.

3.3.1. Nucleus Herd Maintenance. A typical breed structure consists of 3 tiers in the shape of pyramid. Nucleus tier consists of herds that breed their own male and female replacement [39]. Maintaining of nucleus herd has an advantage of utilization as conservation technique for genetic resources, improved accuracy of testing and recording due to a better controlled environment, recording of additional and secondary traits easier, reduction of generation interval, and higher reproduction rate of superior dams [19]. The available herd at Andassa and Metekel ranch will be used as a nucleus herd and superior pure bull source for the village herd at the community level after performance evaluation. Heifers and bulls will be selected based on their pedigree, milk production of their dams, birth and weaning weight, breed characteristics, and general body conformation or morphology [27, 40]. The heifers selected from the performance record will be used as a replacement herd of the nucleus herd, whereas the better performing young bulls will be used as (1) breeding bull for the nucleus herd based on the pedigree and (2) breeding bull for the village herders at the community-based conservation site.
3.3.2. Village Herds. The village herds will be selected from the typical kebele where the pure breed is expected to be available [13]. Willing farmers with Fogera cattle herd will be selected and breeding associations will be built for the use of the selected breeding bull. There will be legal participation rule to subsidize their role in protecting environments and landscapes by maintaining low-input breeds instead of switching to more profitable high-input and high-residue production systems [38]. As the breeding scheme is closed, there will not be a heifer selection for the nucleus herd. But in case, if the nucleus herd will be affected by natural of artificial (human made) problems, there will be a probability of the strategy (Figure 5, broken lines) to introduce better Fogera phenotypes at expected native site of the breed. Performance record will be kept for the evaluations of improvement of the program. In the village herders, the male animals will be castrated for fattening and/or traction power.

3.4. Stakeholders and Their Role in the Conservation and Improvement Program. For better utilization and conservation of AnGR, a well-coordinated institutional arrangement 
TABLE 6: Major stakeholders and their role in the conservation strategy of Fogera cattle.

\begin{tabular}{|c|c|}
\hline Stakeholders & Mandates in the conservation measure \\
\hline \multirow[b]{2}{*}{ Andassa Livestock Research Center (ARARI) } & $\begin{array}{l}\text { (i) Collaborating, leading, and managing the conservation and improvement } \\
\text { measures }\end{array}$ \\
\hline & $\begin{array}{l}\text { (ii) Maintaining a nucleus herd at the center and following implementations of the } \\
\text { strategy }\end{array}$ \\
\hline \multirow{6}{*}{ Regional Livestock Agency } & (iii) Developing data base; analysis and organizing reports \\
\hline & (i) Delivering training for the experts and local farmers at the conservation areas \\
\hline & $\begin{array}{l}\text { (ii) Delivering inputs for the conservation measures, namely, medicaments, Fogera } \\
\text { breed semen, breeding bulls for breeding strategy for restocking, and genetic } \\
\text { improvement measures }\end{array}$ \\
\hline & $\begin{array}{l}\text { (iii) Coordinating the zonal and district level officials on the participation of the } \\
\text { conservation strategies }\end{array}$ \\
\hline & $\begin{array}{l}\text { (iv) Expanding the strategy to other districts, which are expected to be the native } \\
\text { areas of the breed }\end{array}$ \\
\hline & (v)Developing and applying the Fogera cattle usage modality \\
\hline \multirow{3}{*}{ Institute of Biodiversity Conservation } & $\begin{array}{l}\text { (i) Community initiation, mobilization, and budget support for the conservation } \\
\text { strategy }\end{array}$ \\
\hline & $\begin{array}{l}\text { (ii) Participating in the conservation strategies side with ALRC (e.g., working at } \\
\text { Man-Endaba monastery) }\end{array}$ \\
\hline & (iii) Sharing the practices, knowledge, and materials with the research center \\
\hline \multirow{3}{*}{ Universities and international research institutes } & (i) Working side line activities for the conservation strategy \\
\hline & (ii) Working on knowledge based activities that support the strategy \\
\hline & $\begin{array}{l}\text { (iii) Training for proactive community members on further tasks related to the } \\
\text { conservation strategy }\end{array}$ \\
\hline \multirow{3}{*}{ Zonal agricultural offices } & $\begin{array}{l}\text { (i) Developing income generating activities for the selected farmers together with } \\
\text { the research center }\end{array}$ \\
\hline & $\begin{array}{l}\text { (ii) Expanding the model works initiated by the research center to neighboring PAs } \\
\text { and selected native districts of the breed }\end{array}$ \\
\hline & $\begin{array}{l}\text { (iii) Coordinating district and PAs extension workers to work on the conservation } \\
\text { effort via developing a monitoring modality }\end{array}$ \\
\hline
\end{tabular}

is a key issue. The arrangement should include dissemination of information and networking at regional and international level [24]. The number, type, and role of stakeholders participating in the conservation strategy may vary depending on the number and type of activities shared by the conservation measure. The basic points in stakeholder analysis are identifying the direct participants in contact with breed and defining their role $[20,27]$ and accountability of them for their role in the conservation program.

To develop the conservation and improvement strategy and to identify the stakeholders participating in the strategy of Fogera breed, workshop with a theme of "Fogera cattle conservation and improvement program stakeholders meeting" was held by the coordinating effort of ALRC with a finance support of Ethiopian Nile Irrigation and Drainage Project (ENIDP) that participate in various stakeholders at national, regional, and zone to district levels. Two meetings were held in two rounds; the first meeting was a national meeting held at Andassa Livestock Research Center in November 17, 2013, and the second was regional meeting done at Woreta and Gondar towns in June 10-11, 2014. Based on the reports of the meetings, the target actors and their mandates in the conservation measures were summarized in Table 6.
3.5. Related Activities with the Community-Based In Situ Conservation Strategy. Conservation of Farm Animal Genetic Resources (FAnGR) refers to all human activities including strategies, plans, polices, and actions undertaken to ensure that the diversity of FAnGR is maintained to contribute to food and agricultural production and productivity, now and in the future [37]. The conservation and improvement strategy beyond the ideal breeding program need other interventions, notably, access to improved and affordable health services, market information and market services, improved infrastructure, as well as supportive policies, adequate and quality feed resources, and supply all year round [19, 41]. The strategy under implementation should also adopt an integrated approach; that is, the program should include improvement of the production environment, mainly where in situ conservation had been conducted [42]. For the improvement of the production environment, the following strategies will be adopted prior to and side to side with the conservation and improvement strategy developed for Fogera cattle breed.

3.5.1. Feed Development Interventions. A major constraint to livestock production in developing countries is the scarcity 


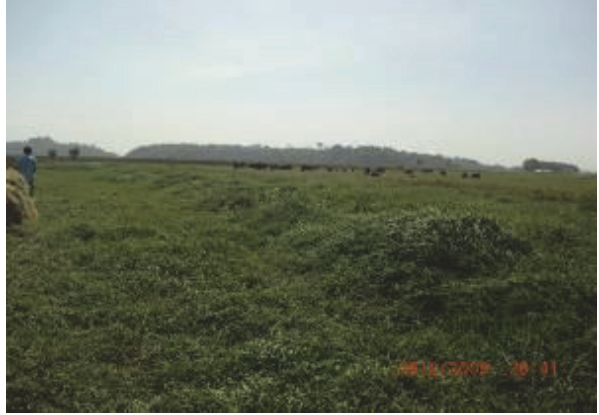

(a)

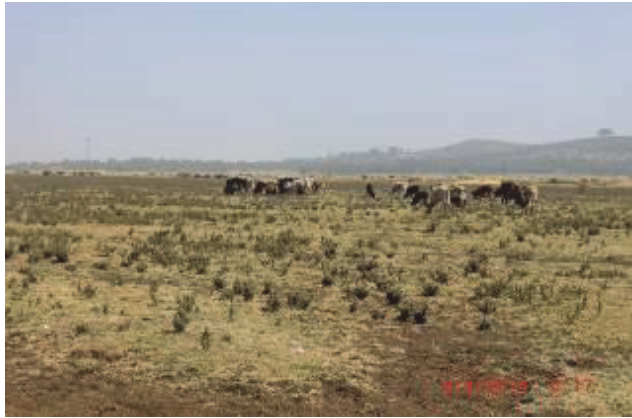

(b)

Figure 6: Assendabo (Phalaris paradoxa) (a) and Amekela (Asteracantha longifolia) invaded grazing land (b).

and fluctuating quantity and quality of the year-round feed supply [43]. Livestock feed is the major constraint for the failure of conservation as well as productivity of a breed $[33,37]$.

As the survey result indicates, feed shortage occurs during April, May, and June of each year based on their severity, and majorly feed development intervention strategies need to be implemented in these months. Fogera district is a potential producer of rice straw for animal feed which is low in its nutritive value and palatability; so urea treatment to improve the nutritive value of the rice straw will be implemented; as the conservation site where the community participation was implemented is water logged area, adaptive grass like the native grass of the area (Figure 6(a)) and other water loving grass cultivars (e.g., densho, and brackia species) will be demonstrated and expanded. Additionally, grazing management (weeding and eradication of unpalatable weeds) (Figure 6(b)) will be conducted for the potential use of the available grazing land. On top of this, backyard forage development with sesbania (Sesbania sesban), elephant grass (Pennisetum purpureum), and other forage trees will be implemented.

3.5.2. Community-Based Animal Health Workers (CAHWs). CAHWs are trained farmers on animal health with closed follow-up by veterinarians to serve the community with low cost per treatment. They have served to fill a large gap in extension services and have enabled more people to access vital information and services to protect the livestock which the formal veterinary services often do not reach. In addition paravets were also considered as more flexible in charging and providing services on credit in emergencies [44]. This intervention has being adopted for 10 years in many African countries to help the pastoralists where the government health workers are unreachable $[44,45]$. The strategy was also evaluated and adopted by Andassa Livestock Research Center for selected watershed areas of Amhara region during 2012/13, and the paravets still serve the farmers. The strategy ensures the work of selected farmers from the villagers after they got practical and theoretical training from ALRC with a least cost per animal. The technicians will be based on AU [46] policy on community-based animal health worker. Adopting this strategy for Fogera cattle conservation and improvement strategy ensures a day to day treatment as well as control of major diseases occurring at the conservation area.

3.5.3. Market Linkage. Field studies in different parts of the highland of Ethiopia show that livestock account for 37$87 \%$ of total farm cash income of farmers, indicating the importance of livestock in rural livelihood [47]. Market provides the mechanism whereby producers exchange their livestock and livestock products for cash [48]. The major livestock marketing constraints are categorized in infrastructural, policy-related, and institutional constraints that include lack of access to formal financial systems and credit, onerous and nontransparent taxation systems, limited investment in communication and infrastructure, poor market supply, and poor forward and backward linkages [47, 49].

The area where conservation was implemented is $30 \mathrm{kms}$ far from Woreta town, capital of Fogera district; this needs a market linkage for the animal products produced from the site. In the market line, fattened bulls which will be culled from the village herd as well as additional milk and dairy product need a market and this will be adopted as a strategy for improving the production environments. Additionally, cooperatives will be developed for marketing their products and to purchase livestock and other agricultural technology.

\section{Conclusion and Recommendations}

Interrelated problems that web the production system of the breed favor the decrement of the population and productivity of Fogera cattle breed. This coupled with availability of unique traits of the breed at the production system seeks for conservation measure; and community-based in situ conservation measure to ensure the participation of the owner of the breeds was designed. For the adoption of the new conservation measure, closed breeding scheme that integrated the two ex situ conservation sites (ALRC and MFCCR) and the village (community) conservation site was developed. To realize the conservation of Fogera cattle, stakeholders like regional livestock agency for assurance of required input, IBC for both financial and knowledge participations, universities and international research institutes for knowledge support, and 
zone and district agriculture offices for direct involvement in the conservation and improvement strategy were analyzed and tasks were shared.

(i) The involvement of stakeholders in the conservation of the breed during the previous years was limited. But now meetings that indicate the participation and support of various stakeholders were done and each stakeholder that had been analyzed and promised to participate in the strategy should honestly and accountably participate to safeguard the asset of the country.

(ii) In many conservation strategies, failure because of lack of community participation and absence of supportive policy and lack of budget was reported and the previous conservation strategies of Fogera breed did not result as expected as the history of the center considered due to similar reasons. Therefore, incentives and subsidies for the community participants (which could be directly or indirectly to create income generating activities) and continuous budgeting system for the research center and the ranch should better be designed and government support towards the strategy should be boldly realized.

\section{Competing Interests}

The authors declare that there is no conflict of interests regarding the publication of this paper.

\section{Acknowledgments}

The authors greatly acknowledge Shiwangezaw Addisu and Gizachew Teshome for feeding and clearing of the data and Taddess Getu, Mulat Lakew, and Eyasu Lakew for their help in collecting the primary data.

\section{References}

[1] S. J. G. Hall, "Conservation of livestock breeds," in Proceedings of the Research Planning Workshop, J. E. O. Rege and M. E. Lipner, Eds., African Animal Genetic Resources: Their Characterization, Conservation and Utilisation, p. 172, ILCA (International Livestock Centre for Africa), Addis Ababa, Ethiopia, February 1992.

[2] J. Fernández, B. Villanueva, R. Pong-Wong, and M. Á. Toro, "Efficiency of the use of pedigree and molecular marker information in conservation programs," Genetics, vol. 170, no. 3, pp. 1313-1321, 2005.

[3] K. McFarlane, G. A. Wilson, and J. S. Nishi, "Management strategies for conservation of genetic diversity in wood Bison (Bison bison athabascae)," File Report 135, University of Alberta, Alberta, Canada, 2006.

[4] N. T. K. Cuc, Strategy to Assess Genetic Diversity and Conserve Vietnamese Animal Genetic Resources Based on Molecular Parameters, Goettingen, Germany, Institute of Animal Breeding and Genetics, Georg-August-Universität Göttingen, 2006.

[5] J. S. F. Barker, "Conservation of livestock breed diversity," Animal Genetic Resources, vol. 25, pp. 33-34, 1999.
[6] A. V. Zárate and A. Markemann, "Community-based breeding programmes incorporating local breeds: concept, research results and implementation strategy on pigs in Northern Vietnam," in Proceedings of the 9th World Congress on Genetics Applied to Livestock Production (WCGALP '10), Leipzig, Germany, August 2010.

[7] A. Tegegne, B. Gebremedhin, and D. Hoekstra, "Input supply system and services for market-oriented livestock production in Ethiopia," in Proceedings of the 14th Annual Conference of the Ethiopian Society of Animal Production (ESAP '06), Addis Ababa, Ethiopia, September 2006.

[8] W. Ayalew and A. Dekeba, "Organization and performance of government-owned cattle breeding ranches in the supply of genetically improved breeding stock in Ethiopia," in Proceedings of the 14th Annual Conference of the Ethiopian Society of Animal Production (ESAP '06), pp. 20-30, Addis Ababa, Ethiopia, September 2006.

[9] N. Alemayehu, G. Gebru, and G. A. Drucker, "Reasons for the Loss of Animal Genetic Resources (AnGR) and the importance of IK in AnGR management," in Proceedings of the 11th Annual conference of the Ethiopian Society of Animal Production (ESAP '03), pp. 37-45, Addis Ababa, Ethiopia, August 2003.

[10] A. G. Drucker, E. Bergeron, U. Lemke, L. T. Thuy, and A. Valle Zárate, "Identification and quantification of subsidies relevant to the production of local and imported pig breeds in Vietnam," Tropical Animal Health and Production, vol. 38, no. 4, pp. 305322, 2006.

[11] IBC (Institute of Biodiversity Conservation), Domestic Animal Diversity, Some of Ethiopia's Domestic Animal Diversity, IBC (Institute of Biodiversity Conservation), Addis Ababa, Ethiopia, 2012.

[12] M. Albero and S. Haile-Mariam, "The indigenous cattle of Ethiopia part-II," World Animal Review, vol. 41-42, pp. 27-34, 1982.

[13] G. Goshu, A. Tegegne, T. Mulugeta, and A. Agdie, "Preliminary report on the distribution of Fogera cattle around Lake Tana, Ethiopia," in Proceedings of the 11th Annual Conference of the Ethiopian Society of Animal Production (ESAP '04), pp. 203-207, Addis Ababa, Ethiopia, 2004.

[14] J. Rege and C. Tawah, "The state of African cattle genetic resources II. Geographical distribution, characteristics and uses of present-day breeds and strains," Animal Genetic Resources, vol. 26, pp. 1-25, 1999.

[15] A. Bitew, A. Kebede, B. Siraw, S. Gizaw, and T. Bimerow, "Conservation-based breeding program for Fogera Cattle," Working Document: Amhara Regional Agricultural Research Institute Andassa Livestock Research Center, 2010.

[16] DAGRIS, Domestic Animal Genetic Resources Information System (DAGRIS). (eds. S. Kemp, Y. Mamo, B. Asrat and Tadele Dessie), International Livestock Research Institute, Addis Ababa, Ethiopia, 2007, http://dagris.ilri.cgiar.org.

[17] A. Bitew, A. Kebede, B. Siraw, S. Gizaw, and T. Bimerow, "Strategies for sustainable utilization of Fogera Cattle in Amhara Region," Strategic Document, Amhara Regional Agricultural Research Institute Andassa Livestock Research Center, 2010.

[18] SPSS for Windows, "Statistical Package for Social Science (SPSS)," Release 16.0. The Apasche software foundation, 2009.

[19] B. A. W. Clemens, "Conserving the biodiversity of Southern African livestock resources," in Proceedings of the Annual Symposium of Developing Areas Branch of the South African Society of Animal Science (SAGAS '95), vol. 16 to 19, Groblersdal, South Africa, October 1995. 
[20] D. L. Patterson and F. G. Silversides, "Farm Animal Genetic Resource Conservation Why and How?" 2003, http://www .cfagrf.com.

[21] FAO (Food and Agriculture Organization of the United Nations), "Smallholders and community-based management of farm animal genetic resources," in Community-Based Management of Animal Genetic Resources. Proceedings of the Workshop Held in Mbabane, Swaziland, 7-11 May 2001, W. Bayer, W. von Lossau, and A. Feldmann, Eds., pp. 1-12, FAO, Rome, Italy, 2003.

[22] IUCN (International Union for Conservation of Nature), Guidelines for Application of IUCN Red List Criteria at Regional Levels: Version 3.0, IUCN Species Survival Commission. IUCN, Gland, Switzerland, 2003.

[23] B. Yitaferu, Land Degradation and Sustainable Land Management Options in the Lake Tana Basin (LTB), Amhara Region, Ethiopia: The Processes of Soil Resource Changes, Natural Resource and Ecology, NCCR North-South, University of Berne, Bern, Switzerland, 2007.

[24] IBC (Institute of Biodiversity Conservation), "The state of Ethiopia's farm animal genetic resources: country report," A Contribution to the First Report on the State of the World's Animal Genetic Resources, IBC, Addis Ababa, Ethiopia, 2004.

[25] A. Bitew, G. Mekuriaw, and M. Tezera, "On-farm evaluation of management practices and productivity of Fogera cattle in Northwest Ethiopia," in Proceedings of the 2nd Annual Regional Conference on Completed Livestock Research Activities, Amhara Regional Agricultural Research Institute (ARARI), Bahir Dar, Ethiopia, 2007.

[26] A. Kebede, L. Yeheyes, T. Eshetie, and G. Zeleke, "Production system shift and land fragmentation on livestock production in fogera district: with special emphasis to the indigenous fogera cattle breed," in Proceedings of the International Workshop on Farm Size Dynamics in East and Southern Africa, Bahir Dar, Ethiopia, June 2013.

[27] J. E. O. Rege, A. Kahi, M. Okomo-Adhiambo, J. Mwacharo, and O. Hanotte, "Zebu cattle of Kenya: uses, performance, farmers preference, measures of genetic diversity and options for improved use," Animal Genetic Resources Research 1, ILRI (International Livestock Research Institute), Nairobi, Kenya, 2001.

[28] K. Zander and J. Mburu, Compensating Pastoralists for Conserving Animal Genetic Resources: The Case of Borana Cattle in Ethiopia, Center for Development Research (ZEF), Bonn, Germany, 2005.

[29] A. Bitew, M. Bahta, K. Mekonnen, and A. Duncan, Dairy Intensification and Milk Market Quality in Amhara Region, Ethiopia, ILRI, Addis Ababa, Ethiopia, 2011.

[30] A. Tegegne, B. Gebremedhin, D. Hoekstra, B. Belay, and Y. Mekasha, "Smallholder dairy production and marketing systems in Ethiopia: IPMS experiences and opportunities for market-oriented development," IPMS (Improving Productivity and Market Success) of Ethiopian Farmers Project Working Paper 31, International Livestock Research Institute (ILRI), Nairobi, Kenya, 2013.

[31] A. Tesfa and S. Mekuriaw, "The effect of land degradation on farm size dynamics and crop-livestock farming system in Ethiopia: a review," Open Journal of Soil Science, vol. 4, no. 1, pp. 1-5, 2014.

[32] J. E. O. Rege, The State of African Cattle Genetic Resources I. Classification Framework and Identification of Threatened and Extinct Breeds, International Livestock Research Institute (ILRI), Addis Ababa, Ethiopia, 1999.
[33] H. Simianer, S. B. Marti, J. Gibson, O. Hanotte, and J. E. O. Rege, "An approach to the optimal allocation of conservation funds to minimize loss of genetic diversity between livestock breeds," Ecological Economics, vol. 45, no. 3, pp. 377-392, 2003.

[34] S. B. Reist-Marti, H. Simianer, J. Gibson, O. Hanotte, and J. E. O. Rege, "Weitzman's approach and conservation of breed diversity: an application to African cattle breeds," Conservation Biology, vol. 17, no. 5, pp. 1299-1311, 2003.

[35] J. Philipsson, J. E. O. Rege, E. Zonabend, and A. M. Okeyo, "Sustainable breeding programmes for tropical farming systems," in Animal Genetics Training Resource, Version 3, 2011, J. M. Ojango, B. Malmfors, and A. M. Okeyo, Eds., International Livestock Research Institute, Nairobi, Kenya; Swedish University of Agricultural Sciences, Uppsala, Sweden, 2011.

[36] AU (African Union) and International Bureau for Animal Resources, "Strengthening the capacity of African countries to conservation and sustainable utilisation of African animal genetic resources," in Proceedings of the Inception Workshop, Abidjan, Côte d'Ivoire, April 2013.

[37] H. Lemma, "Domestic animal biodiversity in ethiopia and its threats and opportunities with emphasis to changing climate: an overview," Advances in Life Science \& Technology, vol. 6, article 33, 2012.

[38] I. Köhler-Rollefson, "Community-based management of animal genetic resources-with special reference to pastoralists," in Proceedings of the Community-Based Management of Animal Genetic Resources Workshop, pp. 13-26, Mbabane, Swaziland, May 2001, http://www.fao.org/3/a-y3970e.pdf.

[39] R. Wakchaure and S. Ganguly, "Multiple Ovulation Embryo Transfer (MOET)-nucleus breeding scheme: a review," International Journal of Engineering and Innovative Technology (IJEIT), vol. 5, no. 2, 2015.

[40] G. Mekuriaw and A. Bitew, "Fogera cattle breeding line/pedigree at Andassa Livestock Research Center," Working Document, Andassa Livestock Research Center, Nairobi, Kenya, 2006.

[41] A. Haile, W. Ayalew, N. Kebede, T. Dessie, and A. Tegegne, "Breeding strategy to improve Ethiopian Boran cattle for meat and milk production," IPMS (Improving Productivity and Market Success) of Ethiopian Farmers Project Working Paper 26, ILRI, Nairobi, Kenya, 2011.

[42] S. Gizaw, K. Awigchew, and A. Yami, "A practical guide on village-based sheep and goat cooperative breeding scheme," Technical Bulletin 42, ESGPIP (Ethiopian Sheep and Goat Productivity Improvement Program), Addis Ababa, Ethiopia, 2011.

[43] IAEA (International Atomic Energy Agency), Improving Animal Productivity by Supplementary Feeding of Multi-Nutrient Blocks, Controlling Internal Parasites and Enhancing Utilization of Alternate Feed Resources. A Publication Prepared under the Framework of an RCA with Technical Support of the Joint FAO/IAEA Programme of Nuclear Techniques in Food and Agriculture, IAEA, Vienna, Austria, 2006.

[44] A. Riviere-Cinnamond and M. Eregae, "Community-based animal health workers in pastoralist areas of Kenya: a study on selection processes, impact and sustainability," Working Paper, Department for International Development, East Kilbride, UK, 2003.

[45] T. Ounga and M. Nyamweya, Training Module for Community Animal Health Workers in Somalia, Final Draft, 2009.

[46] African Union/Interafrican Bureau for Animal Resources, Policy on Community-Based Animal Health Workers, African 
Union/Interafrican Bureau for Animal Resources, Nairobi, Kenya, 2003.

[47] A. Solomon, A. Workalemahu, M. A. Jabbar, M. M. Ahmed, and B. Hurissa, "Livestock marketing in Ethiopia: a review of structure, performance and development initiatives," SocioEconomics and Policy Research Working Paper 52, ILRI (International Livestock Research Institute), Nairobi, Kenya, 2003.

[48] S. Bekure and N. Tilahun, Livestock Marketing Studies, ILCR (International Livestock Center for Africa), Nairobi, Kenya, 1992.

[49] S. Pavanello, "Livestock marketing in Kenya-Ethiopia border areas: a baseline study," Working Paper, HPG (Humanitarian Policy Group), 2010. 


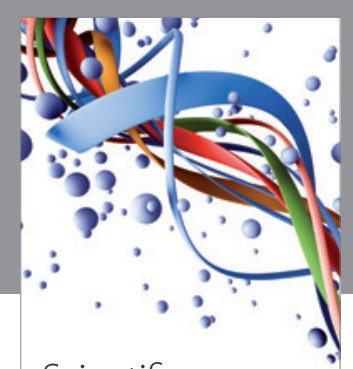

Scientifica
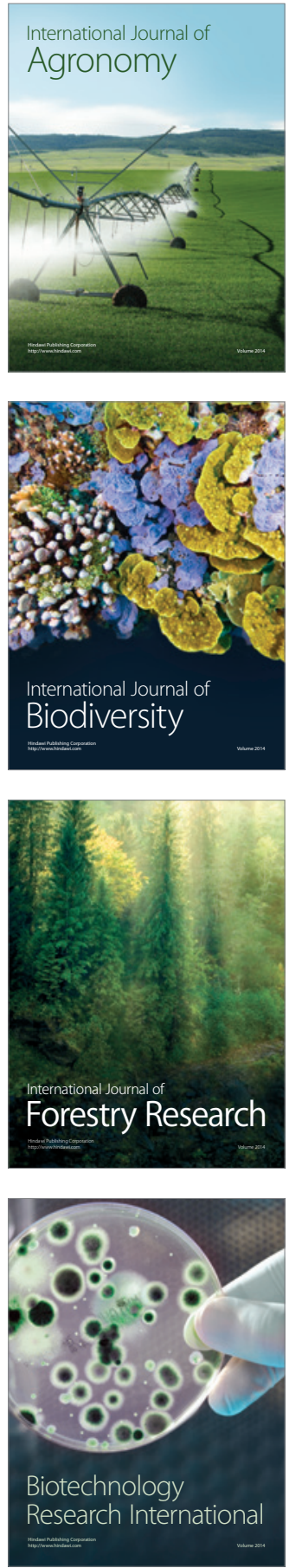
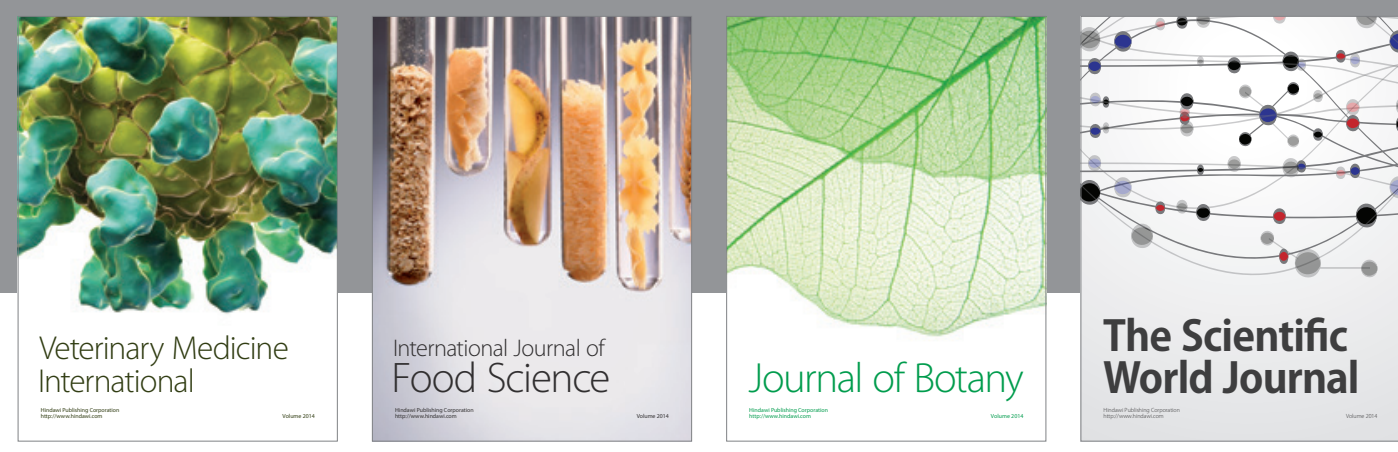

The Scientific

\section{World Journal}

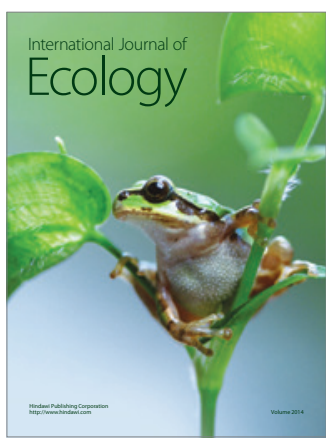

\section{Hindawi}

Submit your manuscripts at

https://www.hindawi.com
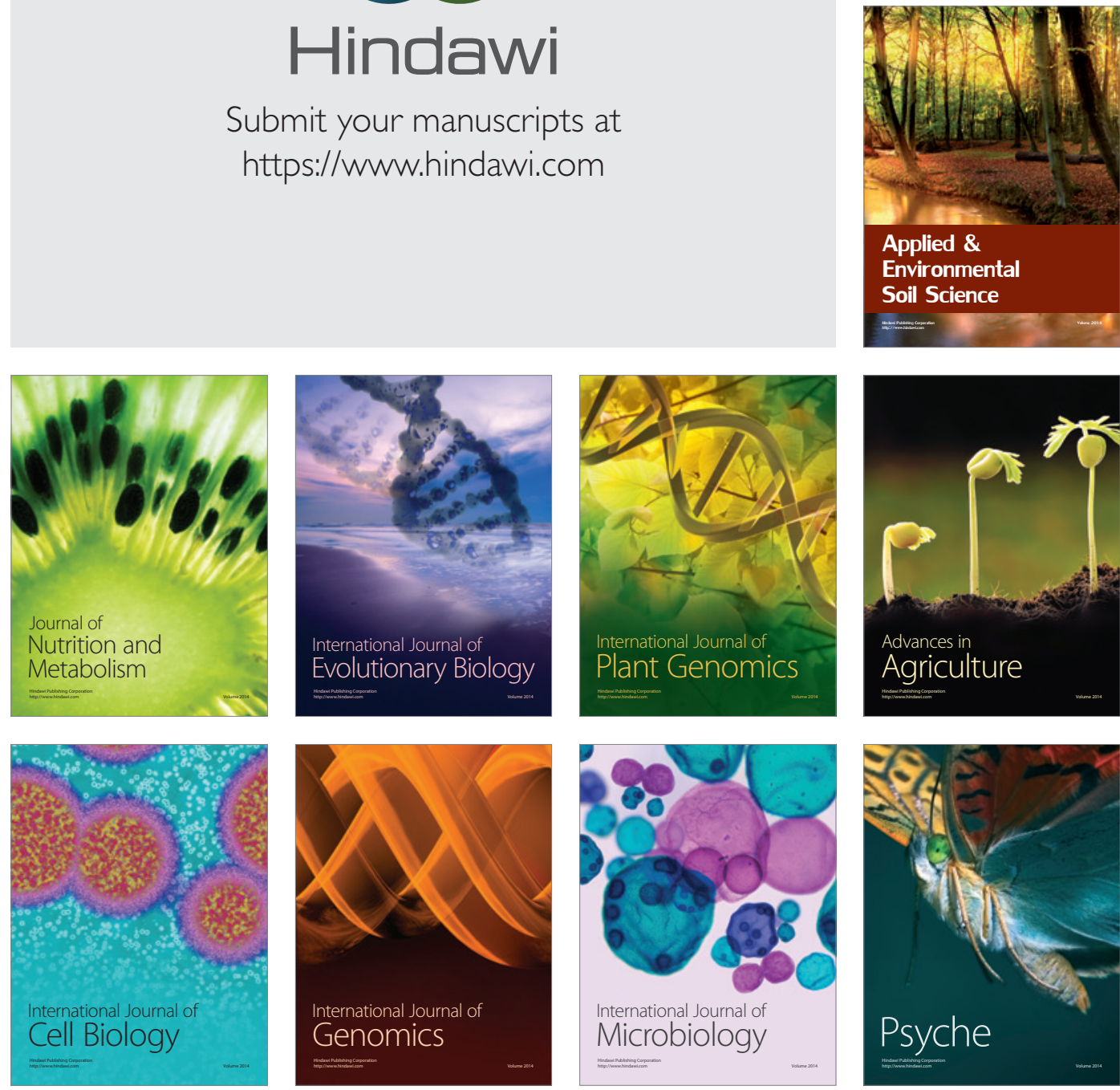
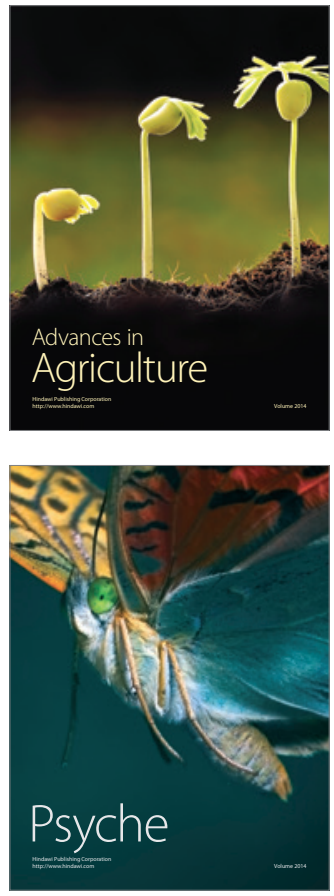